\title{
Lenguaje e ideología. A propósito de la nueva ley del aborto española
}

\author{
Language and ideology. Apropos of the new Spanish abortion draft bill
}

\author{
Raúl Ruiz-Cecilia / raulruiz@ugr.es \\ Universidad de Granada, España \\ Juan Ramón Guijarro-Ojeda / jrgo@ugr.es \\ Universidad de Granada, España
}

\begin{abstract}
This linguistic study examines headlines across Spain's national press featuring the new abortion draft bill from an ideological point of view. In order to achieve this goal, we have compiled a corpus with fifty headlines taken from Spanish written press where the new bill is discussed. Data have been interpreted in the light of the discursive paradigm using, hence, a qualitative methodology. The pragmatic analysis carried out and the discussion of the results evince that right-wing press is antiabortionist while left-wing newspapers defend the organic bill 2/2010 about sexual and reproductive health, and the voluntary interruption of pregnancy. Thus, we may conclude that in Spain, conservative press adheres to current government's abortion policies, while liberal press is against these measures.
\end{abstract}

Key words: language, ideology, abortion, discourse.

Resumen: Este estudio se centra en el análisis de los titulares de prensa relacionados con el anteproyecto de la ley del aborto desde un punto de vista lingüístico e ideológico. Para llevar a cabo este propósito, hemos creado un corpus de cincuenta titulares de prensa donde se alude a la nueva ley que pretende regular el aborto en el Estado español. Los datos se han estudiando a la luz del paradigma discursivo siguiendo una metodología cualitativa. Tras el análisis pragmático y discusión de los resultados, podemos afirmar que los titulares de la prensa conservadora se caracterizan por una postura antiabortista, mientras que los de centro-izquierda defienden la ley orgánica 2/2010. Por tanto, se puede concluir que, en España, la prensa de derechas apoya al gobierno actual en cuestiones relacionadas con el aborto, mientras que la prensa más liberal se opone frontalmente a esas medidas.

Palabras clave: lenguaje, ideología, aborto, discurso. 


\section{Introducción}

Todos estamos familiarizados con la extrapolación común de los conceptos filosóficos de "objetividad" y "subjetividad" y cómo intervienen en los juicios de valor que hacemos sobre las personas, las cosas o las ideas. A veces persiste la obstinación por querer que nuestro juicio prevalezca como el más objetivo y, por ende, como el verdadero. Deseamos exorcizar al otro tachándolo de partidista, manipulador, falseador o tergiversador.

Pero, ante una realidad observable, ¿hay alguna ley universal que nos permita recibir e interpretar el objeto bajo el mismo punto de vista, con exactamente los mismos parámetros? Afortunadamente no. El ser humano filtra cognitivamente el mensaje, y la recepción o reconstrucción que haga de éste con frecuencia se concretará en una visión subjetiva de la realidad. Así, en cualquier materialización del lenguaje humano siempre aflorará una actitud y una intención velada.

El lenguaje de la prensa, por tanto, no escapa a la visión subjetiva. Por mucho que el código deontológico del periodismo $s$ ubraye la veracidad informativa como un deseable, muy rara vez encontramos dos periodistas que redacten una noticia concreta con argumentos similares o con semejantes pormenores. El profesional de la información se refugia en la noticia para hacer llegar a sus lectores su posición ante los hechos que se recogen.

En ese esfuerzo se entremezclan las facetas lingüísticas e ideológicas y se marcan unos idearios para que incidan sobre el receptor. Éste fue el principio regente a la hora de plantear esta investigación sobre el lenguaje de la prensa. El tema concreto que se abordará es el tratamiento de la nueva ley del aborto en cuatro diarios de tirada nacional: El Mundo, El País, ABC y La Razón.

El análisis se centrará en los titulares que proliferaron a finales de 2013 en la prensa española con motivo de la presentación del anteproyecto de ley que lleva por nombre "Ley orgánica para la protección de la vida del concebido y de los derechos de la mujer embarazada" y que, a día de hoy, ha sido paralizada por el equipo del gobierno actual. Para ello, recurriremos a la relación entre ideología y lenguaje como eje vertebrador del trabajo.

\section{Hipótesis y objetivos}

Este trabajo parte de la siguiente hipótesis: "La prensa escrita de ideología conservadora es abiertamente antiabortista al contrario de lo que ocurre con la prensa progresista o de izquierdas". ${ }^{1}$ En estrecha relación con esta hipótesis,

1 La ideología subyacente a los diarios seleccionados es: $E l$ Mundo, centro-derecha; $E l$ Pais, izquierda; $A B C$, derecha; La Razón, derecha. 
nos proponemos los siguientes objetivos: 1) Examinar la corriente ideológica que predomina en cada uno de los titulares periodísticos; y 2) Reconocer el lenguaje metafórico que se utiliza para transmitir la información en relación con la ideología.

\section{Ideología y lenguaje}

Una parte del marco teórico la dedicaremos a comentar algunos estudios previos que han puesto de manifiesto las relaciones existentes entre lenguaje e ideología y que se hicieron más patentes en las últimas décadas del siglo XX. Como muy bien argumenta Gutiérrez Vidrio (1998: 346):

La investigación desarrollada por varias tradiciones, desde la filosofía del lenguaje ordinario hasta la hermenéutica, la semiótica, la etnometodología y la pragmática han puesto de relieve el hecho de que el lenguaje no es sólo un sistema de signos que describen al mundo sino, también, un medio a través del cual los individuos actúan e interactúan en el mundo social. Este reconocimiento del lenguaje como un aspecto central de la vida social y política ha propiciado la reorientación de las teorías sobre la ideología.

Es decir, ideología y lenguaje están íntimamente imbricados y la elección lingüística no suele ser arbitraria sino que frecuentemente encubre un principio ideológico. Los orígenes habría que buscarlos, primeramente, en la teoría marxista a través de la cual se identificaron los relaciones existentes entre los aspectos materiales e ideaciones de la realidad.

Otro precedente lo encontramos en la tradición sociológica de Durkheim (2006) que concibió el lenguaje como semiótica social. Más tarde, Bakhtin y Voloshinov (1989) afirmaron que el lenguaje encarna y articula la experiencia de la lucha social, transición y combate. Ello les llevó a concluir que el signo lingüístico es profundamente ideológico. A tenor de esto, el uso del lenguaje muestra una amplia variedad de orientaciones para los intereses sociales provenientes de posiciones particulares en la sociedad. Silverstein (2003) fue, de igual modo, otro de los precursores en señalar la escisión de la ideología-lenguaje como un campo de estudio nuevo.

Pero, ¿qué se entiende por ideología? Van Dijk (1999: 31) concluye que "[l] as ideologías son un tipo de cognición social compartida" y más concretamente "creencias fundamentales específicas". En otros términos, "la formación de grupos ideológicos generalmente se basa en creencias más fundamentales, lo que por supuesto puede influir en otras, más específicas, de los miembros del grupo" (Ibid.: 31). 
Estas creencias fundamentales se van a hacer extensibles por medio del lenguaje. Van Dijk (1999: 33) apunta que uno de los tipos de relación que se establece entre ideología y lenguaje está formado por "el hecho que las proposiciones ideológicas pueden constituir el significado de las cláusulas oraciones o discursos del lenguaje natural". Esto permitirá que los miembros del grupo puedan acceder directa y libremente a esa ideología concreta.

El autor también destaca cómo "la expresión de las creencias generales (conocimiento, opiniones) controladas por dichas ideologías es un poco menos directa" (Ibid.: 33). Esto provoca que el periodista, por ejemplo, no exponga abiertamente la ideología, sino que la matice pragmáticamente para conducir al lector hacia una interpretación concreta y partidista. Por lo tanto, es por medio del lenguaje que los grupos controlan las ideas y a los individuos. Este ejercicio de transmisión ideológica se llevará a cabo a través de la semántica y de la forma lingüística. Llegado este punto nos gustaría rescatar el lenguaje metafórico de Thompson (1986: 517) cuando observó que las ideas:

no circulan en el mundo social como las nubes en un cielo de verano, volcando ocasionalmente su contenido con el estallido de un trueno o el resplandor de un relámpago. Las ideas circulan en el mundo social más bien como enunciados, como expresiones, como palabras que se hablan o se escriben.

Cabe resaltar las cinco modalidades que este mismo autor estableció para explicar el funcionamiento de la ideología. Así, Thompson (1993: 66-73) menciona:

a) La legitimación: un sistema de dominación se puede mantener si se presenta como legítimo e irrefutable.

b) El encubrimiento o la disimulación: se pueden ocultar, negar o bloquear las relaciones de poder que sirven a los intereses de unos a expensas de los demás.

c) La unificación: abarcaría a todos los individuos de una identidad colectiva ( $s i n$ tener en cuenta las posibles fisuras internas).

d) La fragmentación: la máxima será de esta modalidad sería "divide y gobierna”. Esto se logra sembrando la duda para que se produzca un cisma en los grupos y se opongan entre sí a nivel interno.

e) La reificación o cosificación: en este caso se presentaría una situación transitoria como permanente, natural o atemporal.

El estudio de la ideología también se puede ligar con el análisis argumentativo (Guijarro Ojeda, 2013; Fisher y Gottweis, 2012). En 2003 Gutiérrez Vidrio (2003: 47) publicó un trabajo donde quedan claros los vínculos existentes. Esta autora define la argumentación como "la presión simbólica que un individuo ejerce sobre la audiencia”. Presión simbólica que instintivamente 
nos conduce al mundo de las ideas y, por extensión, al de la ideología. La referencia más clara para adentrarnos en el análisis de la argumentación es la de Grize (1982; 1990; 1996), quien distinguió cinco operaciones lógico discursivas:

a) Operaciones constitutivas del objeto: determinan el tópico.

b) Operaciones de apropiación: afianzan la credibilidad de la esquematización.

c) Operaciones de composición: aseguran la coherencia y cohesión del texto.

d) Operaciones de localización temporal y espacial: ubican espaciotemporalmente a los agentes.

e) Operaciones de proyección valorativa: dejan entrever la subjetividad discursiva del escritor/autor.

Gutiérrez Vidrio (2003) va más allá y combina los planteamientos de Thompson (1993) con los de Grize (1996) para crear su propio modelo de análisis argumentativo. Ésta será una de las referencias a la que recurriremos a la hora de descodificar la ideología latente en los titulares de prensa relacionados con la nueva ley del aborto española. Su propuesta queda reflejada en la ilustración que se encuentra al final del artículo.

Respecto a este tema, nos gustaría hacer referencia a las estrategias que se utilizan en el lenguaje periodístico para promover el proceso persuasivo. Según Sánchez García (2010: 79), las estrategias que el discurso periodístico emplea para persuadir se canalizarían bien subrayando la naturaleza factual de los acontecimientos, bien construyendo una estructura relacional sólida para los hechos, o bien proporcionando información que también posee las dimensiones actitudinal y emocional.

Blommaert (2006) resalta la falta de neutralidad en los actos del habla y que podríamos extrapolar al lenguaje periodístico:

There is no such thing as a "neutral" real language; such a neutral is one metapragmatic categorization among many, though often the one that indexes power, authority, prestige, and status. Furthermore, one of the essential functions of language is ideological (metapragmatic and indexical) framing: providing contextual cues about who speaks, in what mode, on which topic, and under what circumstances.

Otro bloque de referencia a nivel teórico se centra en el lenguaje metafórico de la prensa, pues este también incide en la construcción ideológica. La clasificación que se hará de la metáfora partirá del estudio clásico de Lakoff y Johnson (2007). Las primeras que se mencionan son las llamadas metáforas estructurales y que se definen como la estructuración de un concepto en términos de otro.

El segundo tipo se le conoce como metáfora orientacional. Ésta "no estructura un concepto en términos de otro, sino que organiza un sistema 
global de conceptos con relación a otro [...]. [L]a mayoría tiene que ver con la orientación espacial: arriba-abajo, dentro-fuera, delante-detrás, profundo-superficial, central-periférico" (Ibid.: 50). A estas dos hay que sumar las metáforas ontológicas. En este caso se considerarían los "acontecimientos, actividades, emociones, ideas, etc., como entidades y sustancias” (Ibid.: 64).

Dichas metáforas hacen que el emisor pueda elegir partes de su experiencia "y tratarlas como entidades discretas o sustancias de un tipo uniforme. Una vez que hemos identificado nuestras experiencias como objetos o sustancias, podemos referirnos a ellas, categorizarlas, agruparlas y cuantificarlas, y, de esta manera, razonar sobre ellas" (Ibid.: 63).

\section{Metodología}

El presente trabajo se sustenta en el manejo de un corpus de titulares periodísticos recogidos de la prensa escrita en el periodo comprendido entre el 18 y el 23 de diciembre de 2013. Estas fechas coinciden con el debate previo y posterior que se originó en la opinión pública por la aprobación del anteproyecto de la nueva ley del aborto por parte del PP, la cual quedó paralizada en septiembre de 2014. En total contamos con 50 titulares de cuatro diarios españoles (El Mundo, 13 titulares; El Pais, 16 titulares; $A B C, 12$ titulares y La Razón, 9 titulares). Al final del presente trabajo, en el Anexo, aparece la tabla con el corpus que analizamos.

Todos los titulares se examinaron tomando como referencia la relación entre lenguaje e ideología y cómo la segunda se vale de la primera para transmitir el mensaje. Para ello, y siguiendo los preceptos de la metodología cualitativa, se extrajeron categorías léxicas recurrentes en el corpus que se manejó (por ejemplo, el concepto de "derecho", "reacciones del PP y PSOE" "vida”, etcétera).

Enseguida, éstas fueron analizadas a la luz del esquema integrativo propuesto por Gutiérrez Vidrio (2003), donde confluyen el modelo de operaciones lógico-discursivas ideado por Grize (1982) y los cinco modos de operación de la ideología postulados por Thompson (1993) (incluido en el Anexo de este trabajo).

Para examinar los titulares y articularlos con el planteamiento ideológico, se profundizó en la elección léxica, los rasgos lingüísticos y los tipográficos que el autor empleó para reforzar su punto de vista. Esto facilitó las comparaciones y los contrastes entre las noticias de los distintos diarios, además de favorecer la simplificación de los datos.

En estrecha relación está el estudio del lenguaje desde una perspectiva 
metafórica y que constituyó otra fase de análisis. La clasificación que utilizamos fue la de Lakoff y Johnson (2007), quienes distinguían entre metáforas estructurales, orientacionales y ontológicas. En esta fase se observó la canalización de la ideología a través de dicha figura retórica.

\section{Análisis del corpus y resultados}

Señala la investigadora Gutiérrez Vidrio (1998) que para un estudio de la posición ideológica en la prensa es conveniente centrarse en las operaciones de apropiación y en las de proyección valorativa (Grize, 1982, 1990, 1996), pues es donde más claramente se manifiesta la ideología. No obstante, en nuestro caso, las operaciones constitutivas del objeto no tienen sentido ya que sólo abordamos un tema: la nueva ley del aborto que el PP ha propuesto y que será sometida a trámite parlamentario. Las dos restantes ("operaciones de composición" y "operaciones de localización") tampoco son pertinentes puesto que este estudio lo ceñimos únicamente a los titulares.

Centrándonos en la primera categoría, “operaciones de apropiación”, vemos cómo son varios los titulares que recurren a esta estrategia para dar credibilidad a la noticia; y, en consecuencia, las determinaciones de los objetos se presentan como irrebatibles. Las referidas operaciones son muy frecuentes en nuestro corpus. Así, todos los diarios intentan reflejar la realidad y veracidad de la noticia, pero valiéndose de recursos lingüísticos que esconden efectos muy diferentes.

Por ejemplo, El Mundo afirma que La ley del aborto coloca a España a la cola de Europa legitimando la información al contrastarla con otras leyes similares existentes en Europa. El resto de periódicos obvia esta indagación y se circunscribe a los principios constitutivos más polémicos de la ley. De igual modo, la evaluación comparativa que hace el periódico se enmarcaría dentro de las "operaciones de proyección valorativa" de Grize (1996) y se relacionaría directamente con el modo de "simulación" de Thompson (1993).

Son tres los titulares que recogen la palabra "derecho" y en la mayoría de los casos aparece entrecomillada, ya que quieren transmitir a los lectores que esa información la han dicho otros, no ellos. En la noticia ELM 3, el periodista cita las palabras del PP señalando con comillas simples "derecho", dirigiendo de esta forma la atención del lector hacia una postura concreta. Es llamativo que se excluya de la cita la palabra "excepción" que también fue pronunciada por el gobierno popular, pero que El Mundo parece no compartir. 
La Razón, sin embargo, plasma la noticia con el siguiente titular PP: el aborto «nunca puede ser un derecho» sino una «excepción» (LAR 1).

Aquí se pretende dar veracidad al tema reproduciendo la literalidad del discurso pero ampliando las comillas a adverbios absolutos como "nunca" y a un sustantivo que comparte la derecha española "excepción". Además, es destacable el uso de los dos puntos después de la palabra "PP” y que, desde mi punto de vista, presentan la postura de este partido político de forma contundente y directa, sin circunloquios ni eufemismos.

$A B C$ también recoge esta parcela informativa pero valiéndose del estilo indirecto introducido por el verbo dicendi, "decir". El País, por su lado, no profundiza en esta arista porque, como veremos, opta por una visión más proabortista, donde el derecho a decidir es su base argumentativa.

Otra unidad temática está representada por la respuesta que el PSOE declamó cuando se presentó el anteproyecto de la ley en el Consejo de Ministros. El diario El Mundo da credibilidad a su esquematización utilizando comillas en palabras clave: El PSOE promete 'parar' la 'ley del aborto dictada por la extrema derecha'(ELM 5). La primera parte de la cita fue pronunciada por la vicepresidenta del PSOE, Elena Valenciano; mientras que la segunda parte corresponde a la secretaria de Igualdad de esta formación política, la feminista Purificación Causapié.

El Pais lo plasma con la noticia: El PSOE promete parar la ley del aborto que trata a las mujeres como "incapaces" (ELP 11). Se acentúa el adjetivo "incapaces" para que quede clara la correlación que promueve la derecha y de la cual este periódico no participa. En términos similares se expresa La Razón, pero sustituyendo el verbo "prometer" por "comprometer" y entrecomillando el verbo "parar": El PSOE se compromete a «parar» una ley que trata a las mujeres como «incapaces» (LAR 9).

A pesar de la similitud de los titulares y de encontrarnos ante dos actos ilocutorios, según la Teoría de los actos del habla, de Searle (1990: 32), el verbo "comprometer" implica una responsabilidad mayor para el partido político que el verbo "prometer". El DRAE (2016) define el primero como "constituir a alguien en una obligación, hacerse responsable de algo" o "contraer un compromiso". El segundo se concibe como "obligarse a hacer, decir o dar algo". Es decir, La Razón le impone una obligación dando a entender que no serán capaces de cumplirla (ven improbable que ganen las elecciones).

Además también deja claro que ellos no llaman a las mujeres "incapaces". Esa conceptualización ha salido de los representantes socialistas. $A B C$ recoge esta información con el siguiente titular: El PSOE frenará una ley que han hecho «los enemigos de las mujeres». Una vez más, estamos ante un ejemplo 
de toma de distancia, ya que el diario quiere dejar claro que las palabras entre comillas han sido pronunciadas por otros y que ellos se limitan a informar a sus lectores.

Otro grupo informativo afecta a la votación secreta de la ley en el Parlamento. Sólo aparece en dos periódicos. El País lo formula: El PSOE apela a las diputadas del PP y pedirá voto secreto en la ley del aborto (ELP 8). Entre tanto, $A B C$ lo plasma en el enunciado: El PSOE insta a las 76 diputadas del $P P$ a rechazar la reforma del aborto (ABC 5).

Las operaciones de apropiación a las que recurren los respectivos periodistas son disímiles. ELP 8 utiliza el verbo "apelar" que, según el DRAE (2016), se define como " $\mathrm{r}$ ] ecurrir a alguien o algo en cuya autoridad, criterio o predisposición se confía para dirimir, resolver o favorecer una cuestión." Es decir, la intención del partido político es convencer al sector femenino de la oposición para que vote en contra de la nueva ley del aborto.

Para ello se construye una perspectiva de diálogo entre el proponente y su oponente utilizando como mecanismo el voto secreto. ABC 5, sin embargo, emplea el verbo "instar" que lleva implícito un matiz repetitivo y de insistencia que pudiera parecer desmesurado ante los ojos del lector. Además, añade el número de diputadas del PP para demostrar que conoce bien el reparto de escaños en el Congreso. Cabe añadir que se fragmenta la noticia para omitir una carga informativa importante: la del voto secreto que permitiría, según el PSOE, mayor libertad a la hora de votar esta ley, sin atenerse a la disciplina de voto.

El análisis ideológico se centrará ahora en el concepto de "vida" que barajan los distintos diarios. Los titulares en los que nos vamos a detener son: Derecho a Vivir critica que la ley permita abortar a una violada porque 'castiga a un inocente' (ELM 4); Las asociaciones pro vida, satisfechas con la reforma (ABC 10); El triunfo de la vida ante la adversidad. Compromiso con la vida (LAR 2); Entre 1985 y 2011 se han practicado 1,7 millones de abortos en España (LAR 3); y La «defensa de la vida» del PSOE: un aborto cada cinco minutos (LAR 5).

El diario que más páginas dedica a este tema es La Razón. Para ello se sirve de operaciones de apropiación que darán credibilidad a la noticia y legitima la información con citas textuales o con datos precisos que refuerzan la intención comunicativa. En LAR 3 recoge la cifra de abortos legales que se han dado en España desde que se aprobó la primera ley en 1985. El dato comprende hasta el final del gobierno de Zapatero y omite los dos años más recientes de gobierno popular, dando a entender que el aborto es una medida socialista. 
Por otro lado, es reseñable el uso de comillas en LAR 5, donde manifiestamente el diario quiere dejar en evidencia al PSOE al marcar "defensa de la vida" (el mensaje pasa a leerse "su defensa de la vida", no la nuestra). Además presenta como irrefutable el número de abortos que se producen en España (uno cada cinco minutos) y señala como únicos culpables a los gobiernos de izquierda precedentes.

El periódico, claramente, fragmenta la realidad y moviliza el sentido para despertar una actitud reaccionaria entre los lectores. La ironía latente contribuye a crear un microuniverso parcial, selectivo y estratégico. Otro titular de La Razón incluye operaciones de proyección valorativa: El triunfo de la vida ante la adversidad. Compromiso con la vida (LAR 2). Elige las palabras "triunfo" y "compromiso" con carga semántica positiva que refuerzan la posición del escritor respecto al aborto.

Los pro-abortistas quedan implícitamente definidos como los enemigos. Finalmente, El Mundo y $A B C$ se centran en las asociaciones pro-vida y exponen dos posturas complementarias. El primer diario se vale de citas textuales para validar la información y entrecomilla "castiga a un inocente" con el fin de desligarse ideológicamente de esa concepción de la vida. En un segundo titular, Alarma entre las mujeres y satisfacción en los provida (ELM 11), este periódico contrapone dos posturas valiéndose de la antítesis ("alarma" versus "satisfacción").

En este caso, la ideología aparece simulada bajo un tropo. Cabe advertir que en el sustantivo elegido por el periodista para referirse a la postura de las mujeres queda implícito un compromiso mayor que en el seleccionado para dirigirse a los pro-vida. $A B C$, por su parte, se vale de una estructura sintáctica sencilla con el verbo principal omitido para crear un efecto estilístico que potencie la información. La coma que separa ambos segmentos afianza la significación ideológica latente: las asociaciones pro-vida, minoritarias en España, están contentas con la propuesta del PP.

Otro importante núcleo temático lo constituyen las referencias al contenido mismo de la ley. El periódico que más titulares dedica a este análisis es El Pais. La noticia: Ni rastro de las medidas contra la "violencia estructural"(ELP 2) rescata las palabras que el ministro Gallardón empleó en marzo de 2012 para argumentar sobre las posibles razones que llevan a la mujer a abortar.

Esta "violencia estructural" es uno de los reproches que el diario hace al gobierno y para ello entrecomilla el concepto. Implícitamente lo está acusando de no ser coherente con su discurso. En el titular: Se probibe la publicidad de las clinicas que hacen abortos (ELP 3), se destaca un rasgo que pasa desapercibido para el resto de los periódicos. La información se presenta de forma 
irrefutable y el escritor se vale del mismo verbo que aparece en el anteproyecto de ley ("prohibir") con una alta carga semántica restrictiva, la cual se quiere compartir con los lectores.

El resto de noticias de este diario se concentra en los supuestos que legitimarán el aborto en España. En: Anomalias gravísimas e incurables pero no mortales, sin amparo (ELP 5), nos encontramos con una proyección valorativa evidente que viene dada por la forma superlativa del adjetivo "grave", la conjunción adversativa "pero" y la expresión "sin amparo". Además, la secuencia adjetival "gravísimas", "incurables" y "mortales" exalta la interpretación insolidaria de la ley.

En relación con la estructura formal del enunciado, es conveniente señalar el efecto que crea la coma que separa ambas partes de la oración. La pausa está situada ahí intencionadamente para que el lector recupere el aliento antes de leer el veredicto final. La suma de todos estos ángulos interpretativos tiene como resultado una oposición frontal al anteproyecto de ley.

Otras dos noticias que se refieren a la malformación son: Las verdades a medias para limitar el supuesto de malformación (ELP 9) y La violación si es un supuesto, la malformación no (ELP 12). En ELP 9 se observa cómo el periodista se ha apoyado en una operación de proyección valorativa mediante la evaluación de la información. Las verdades a medias se autoanulan y se convierten en mentiras. El diario pretende erigirse como la fuente de referencia para que el público sepa que el gobierno no dice toda la verdad.

El siguiente titular (ELP 12) opera en la misma línea aunque esta vez se ajusta a la información factual sin ningún referente valorativo evidente. El adverbio "sí" colocado estratégicamente para que tenga una función intensificadora (perfectamente podría haberse omitido) deja entrever una apreciación valorativa importante. Además, la oposición que se establece entre las dos oraciones yuxtapuestas encubre una postura concreta: es un disparate que se omita la malformación como supuesto para el aborto.

El País concluye su análisis de contenido con dos noticias más: El supuesto de salud lo abarca casi todo (ELP 15) y Un proceso lleno de obstáculos (ELP 14). Ambas albergan la idea de "obstrucción". El primer titular evalúa la información con la expresión "lo abarca casi todo", lo cual indica que serán pocos los argumentos que se escapen al supuesto de salud. Todo esto nos llevaría a la conclusión que se recoge en el segundo titular: el proceso no va a ser fácil.

Como se puede apreciar, la crítica subyacente se identificaría con la ideología de la izquierda. Una última noticia que se recoge en El País es: Decálogo de la "Ley de Protección de la Vida del Concebido" (ELP 16). Claramente, el periodista activa el interés del lector por querer saber más sobre los preceptos 
que operan en la nueva ley, pero no lo hace de una forma aséptica, sino llamando la atención sobre el polémico nombre de la ley. Se utilizan las comillas para que no pasen desapercibidos los conceptos clave "vida" y "concebido". Curiosamente, los matices que más frecuentemente se relacionan con la palabra "concebido" son de índole religiosa. ${ }^{2}$

El Mundo parece optar por una interpretación más distante y no se posiciona respecto a los dos supuestos que recogería la nueva ley. En cambio, sí alude al tiempo de reflexión antes de poder abortar: La mujer deberá reflexionar 7 dias antes de abortar (ELM 7). En este caso se da veracidad a los argumentos recogiendo el dato directamente del anteproyecto, aunque el periodista sí que se toma la libertad de introducirlo con el verbo "deber".

Semánticamente, tiene una carga valorativa importante dado que denota obligatoriedad e imposición externa. Desde otro ángulo, cabría preguntarse cómo puede evaluarse la reflexión si ésta es una tarea meramente cognitiva y, por ende, inmensurable. Una visión más personal nos lleva a señalar la intertextualidad religiosa que subyace tras el número siete. Para la fe cristiana, el siete simboliza, entre otros, la perfección, las virtudes, ${ }^{3}$ los sacramentos, ${ }^{4}$ los pecados capitales 5 y la creación del mundo.

En el anteproyecto de ley, tal y como se expone en el titular, se opta por el número en vez del sinónimo "semana" que en este contexto tendría el mismo valor y rompería cualquier conexión intertextual. Las dos noticias restantes se focalizan en la parte médica de la ley y enfatizan la nueva exigencia legal. Por un lado, en el titular: La nueva ley del aborto 'exige' riesgo psíquico para la madre (ELM 8), el periodista emplea comillas simples para realzar la palabra "exige".

Este marcador hace que las connotaciones del verbo pasen a un primer plano y quede descubierta la apreciación valorativa del escritor. El mismo efecto produce el adverbio "sólo" en el siguiente titular: Las mujeres sólo podrán abortar con dos informes psiquiátricos (ELM 10). El Mundo se inclina por el trámite médico-administrativo pero omite el paso previo de los supuestos sin el cual la mujer no podrá llegar a solicitar los informes psiquiátricos. Es decir,

2 Según el Corpus Diacrónico del Español (CORDE, 2016), el 19,41\% está vinculado con la prosa religiosa; el 18,92\% con la prosa narrativa; el 16,74\% con la prosa histórica; el $14,64 \%$ con la prosa científica; el $11,10 \%$ con la prosa didáctica; el 5,83\% con la prosa de sociedad; el 3,34\% con la prosa jurídica; el 3,34\% con el verso lírico; el 1,61\% con el verso dramático y en la categoría de "otros" habría un 3,16\%.

3 Humildad, generosidad, castidad, paciencia, templanza, caridad y diligencia.

4 Bautismo, confirmación, eucaristía, penitencia, unción, orden, matrimonio.

5 Avaricia, gula, lujuria, pereza, ira, envidia y soberbia. 
se esboza una postura pro-abortista pero no tan abierta como la que aparece en El Pais.

$A B C$ es otro de los periódicos que se adentran en el análisis interno de la nueva ley. Son tres los titulares a los que recurre para sintetizar las novedades: Doce preguntas y respuestas para entender la reforma de la ley del aborto ( $\mathrm{ABC}$ 1); Diferencias entre las reformas del aborto del PSOE y del PP (ABC 8); y El aborto se limita al riesgo grave para la salud de la madre y a la violación (ABC 9). Son palpables las diferencias de este diario con el anterior.

En este caso, la noticia se encauza hacia la comprensión y justificación de la nueva ley y la crítica de las anteriores (ambas propuestas por el PSOE). El lector ya no se enfrenta con titulares alarmistas como pudieran ser los de $E l$ País o, de forma más moderada, los de El Mundo. Aquí se parte de la idea de que la reforma era necesaria y, por lo tanto, se limita a hacerla comprensible para el ciudadano. La ideología operaría mediante la legitimación y universalización, y encajaría en las operaciones de apropiación de Grize (1996).

La credibilidad viene garantizada por el esquema argumentativo que se selecciona: preguntas y respuestas para evitar que nada quede en el aire. El titular $\mathrm{ABC} 8$ contiene una operación de proyección valorativa al comparar las leyes orgánicas del aborto anteriores (9/1985 y 2/2010). Obviamente, las diferencias favorables a la línea editorial del periódico serán las que se destaquen para evitar conflictos ideológicos con los lectores.

En ABC 9, el aborto se aborda desde la excepción y se subraya que ocasionalmente la mujer podrá abortar si se dan condiciones muy concretas. La proyección valorativa del titular queda esbozada con el verbo "se limita", que rápidamente induce a pensar que el asunto queda controlado e inmejorablemente acotado.

Una nueva parcela informativa afecta a la despenalización del aborto para la mujer. $A B C$ utiliza un esquema expositivo-explicativo para recalcar un gran avance democrático: la gestante no tiene responsabilidad alguna en el aborto. Según Grize (1996), en este caso priman las operaciones de proyección valorativa, ya que el diario anuncia que va a ir más allá de la información fáctica para enfatizar la novedad: Claves y nuevos requisitos para acreditar el aborto despenalizado por parte de la mujer (ABC 7).

El País plasma la noticia en el siguiente titular: El aborto fuera de la ley será un delito sin sanción para las gestantes (ELP 6). Aquí se desprovee la información de todo atavío de novedad y se construye un campo léxico relacionado con la (i)legalidad: "fuera de la ley", "delito" y "sin sanción". 
La postura que defiende es claramente contraria a la medida, pues si la acción queda al margen de la ley, ella también tiene que compartir la responsabilidad. Por lo tanto, aunque a priori pudiera parecer que el periodista sólo comparte información, el modo de articular y combinar el lenguaje lleva consigo una intencionalidad añadida.

Abrimos un nuevo núcleo temático que podríamos denominar "promesas y reproches políticos". $A B C$ dedica buena parte de sus titulares a alabar la tarea política del PP. Así, nos encontramos con Rajoy cumple con la reforma del aborto (ABC 6), «Iba en nuestro programa electoral y está en la misma linea que la ley aprobada por el PSOE en 1985» (ABC 12); o Mejora la ley, la tarea continúa $(\mathrm{ABC} 4)$.

El primero y el segundo están íntimamente relacionados, aunque en uno predomina la operación de proyección valorativa ("cumple"); en tanto, en el otro se legitima la información con una cita directa-modificada del presidente Rajoy. ${ }^{6}$ Mientras que el periódico felicita al PP por ser fiel a su programa electoral, el partido político se excusa retrotrayéndose a una ley de los años ochenta con la lectura añadida, "no somos los únicos, ellos también lo hicieron".

Las palabras del ministro de Justicia quedan igualmente reflejadas en la noticia Gallardón: «El PSOE rompió el consenso con la ley de plazos» (ABC 11). La fuente queda perfectamente identificada y las palabras despiertan el discurso "hereditario" de la legislatura anterior. $A B C$ justifica así la reforma, pues la oposición quebrantó la unidad y, por ende, la intención comunicativa los señala como los auténticos culpables.

El Mundo y El País hacen una evaluación de la ley desde dos ángulos opuestos. Uno alaba la legalidad de la reforma: Una ley más adecuada a la doctrina del TC (ELM 9) y el otro la cataloga como la norma más restrictiva desde 1978: El Gobierno aprueba la ley del aborto más restrictiva de la democracia (ELP 1). Estas mismas palabras las recoge El Mundo en el siguiente titular: La izquierda y los nacionalistas coinciden: «Es la norma más restrictiva de Occidente» (ELM 12). La credibilidad de la esquematización se ha conseguido en este caso por medio de una operación de apropiación (cita textual).

6 Las palabras textuales serían: "Eso era algo que iba en nuestro programa electoral y hemos hecho una regulación que supongo se presentará hoy tras su aprobación por el Consejo de Ministros, en la misma línea de la ley del 85 que rigió en España durante 20 años y que fue aprobada bajo los gobiernos de Felipe González". [http://www.europapress.es/epsocial/ noticia-aborto-rajoy-hemos-hecho-regulacion-misma-linea-ley-1985-20131220135600. html] 
El matiz religioso es igualmente motivo de análisis periodístico. El País se vale de una cita directa que da peso a la postura pro-abortista: "Católica o no, la mujer debe ser libre de decidir si aborta" (ELP 10). La primera parte del titular expone la tesis y seguidamente la niega para hacerla extensible a cualquier confesión religiosa. La protagonista de la noticia es la mujer, agente central del proceso.

La Razón, sin embargo, recurre a la posición de la curia eclesiástica para abordar la noticia: Para la Conferencia Episcopal, «dentro de lo malo, es menos malo» (LAR 4). De nuevo, la información se legitima por medio del estilo directo y deja claro que la iglesia católica ve con buenos ojos la medida aunque le gustaría que fuera más estricta.

El titular ELP 13 recoge la opinión del colectivo femenino con una cita directa "Somos maduras para decidir solas sobre el embarazo". Aunque a priori el uso de las comillas pudiera indicar un distanciamiento ideológico por parte del periodista, vemos que nos presenta el titular sin citar la fuente. Esto acerca la posición del diario y la del colectivo que la expresa. La ideología también se manifiesta en este titular por medio del modo de unificación, ya que recurre a una opinión para simbolizar la postura de las mujeres ante la nueva ley del aborto.

\section{El lenguaje metafórico en los titulares}

La eficacia de los recursos teóricos es manifiestamente reconocida por los analistas del lenguaje periodístico y político. Como muy acertadamente indica Zorrilla Barroso (2002: 112-113).

El empleo del lenguaje figurado en los titulares obedece a varias razones periodísticas, además de a la necesidad de llamar la atención del lector a través de la función apelativa, como es la posibilidad de adaptar el texto al espacio disponible y el deseo de mostrar un estilo propio e identificable. (...) [L]os tropos se emplean en los titulares para crear imágenes sugestivas y enriquecedoras de la expresión si se manejan con maestría narrativa. Por el contrario, también pueden resultar una vía fácil para la penetración de la retórica en el lenguaje periodístico con fines interesados y manipuladores de la información. Esa tentación es mayor aún en los titulares que se ven obligados a condensar gran cantidad de información con pocos recursos lingüísticos y pueden encontrar en los tropos la oportunidad de aplicar intencionadamente un lenguaje cargado de retórica a los textos de cabecera.

Nosotros nos hemos inclinado por el examen de la metáfora en el corpus que compone este estudio. Uno de los titulares donde encontramos este tropo es: La ley del aborto coloca a España a la cola de Europa (ELM 1). En este caso 
se utiliza el lenguaje metafórico para referirse a las consecuencias que tendrá para España la ley sobre el aborto que el PP pretende aprobar en esta legislatura. El Mundo augura un retroceso importante respecto al ámbito europeo y por ello se atreve a afirmar que España será la última dentro de la Unión Europea.

La metáfora "colocar a la cola", siguiendo la clasificación de Lakoff y Johnson (2007), sería orientacional, pues "no estructuran un concepto en términos de otro, sino que organizan un sistema global de conceptos con relación a otro" (Ibid.: 50). Según Sánchez García (2009: 168), se aplicaría la analogía: "es positivo lo que tenemos delante porque es lo que está a la vista, mientras que tendemos a desconfiar de lo que está en un segundo plano, porque está oculto".

Estar a la cola es quedarse atrás y, por ende, supone un retroceso importante. Esto se enlazaría con la segunda noticia del diario El Mundo (Pasar a la prehistoria, ELM 2) donde, de nuevo, tenemos un uso metafórico orientacional para indicar que la ley implica volver hacia atrás, a una época muy remota donde el aborto se planteaba en otros términos. Esta idea de regresión también es tratada metafóricamente en El País con un titular similar: Regreso al pasado (ELP 7). Una vez más, deshacer lo ya andado es negativo y perjudicial para la nación española.

Otra metáfora la encontramos en El Pais con la noticia: La oposición y las organizaciones feministas cargan contra la reforma, donde se introduce el elemento batalloso "cargar contra" para la futura ley del aborto. En este caso, estaríamos ante una metáfora estructural, puesto que se ordena un concepto (el rechazo social de la ley) en términos de otro (el inicio de una pugna para detener la reforma).

En el titular: El PP aplaude la «seguridad jurídica» y el «peso» médico (ELM 13) se vislumbra una metáfora ontológica. Hay una atribución directa de acciones humanas a un concepto abstracto como sería el partido político y al objeto directo donde recae la acción del verbo.

La Razón emplea una metáfora ontológica de recipiente en el titular: Fin al coladero del aborto (LAR 6). Según Sánchez García (2009: 172), “[1] as metáforas de recipiente se diferencian del resto de metáforas ontológicas en que tienen su fundamento en una orientación DENTRO-FUERA. En este caso particular, aparte de cosificar determinados conceptos, se incide en las posibilidades de albergar algo en su interior o de vaciarse". Por eso, la nueva ley tendrá una estructura mucho más tamizada para impedir que se cuelen organismos no-natos. Por lo tanto, todo lo que quede dentro es bueno, lo malo es aquello que se filtra. 
Otro ejemplo de lenguaje metafórico lo encontramos en: Un proceso lleno de obstáculos (ELP 14). El periodista concibe el protocolo que establecerá la nueva ley sobre el aborto como un camino sinuoso plagado de impedimentos y óbices. Según la clasificación de Lakoff y Johnson (2007), estaríamos ante un modelo de metáfora orientacional donde queda implícito que la mujer se verá obligada a corregir repetidamente su rumbo antes de conseguir el permiso para abortar.

Este mismo diario nos brinda un ejemplo más de metáfora ontológica al atribuir cualidades humanas a realidades no animadas o abstractas. De este modo, la personificación que se haya en el titular: El supuesto de salud lo abarca casi todo (ELP 15) viene dada por el verbo "abarca", que atribuye al "supuesto de salud" una cualidad de posesión ajena a su significado. Con la utilización de esta comparación, se magnifica el poder de uno de los supuestos contemplados en la próxima ley del aborto.

El diario El Mundo utiliza otra metáfora ontológica en el titular: Partidarios de la sanidad pública tachan de 'sádica' la nueva ley del aborto (ELM 6). La figura retórica se localiza en la expresión "tachan de sádica”. A la ley le son atribuidas cualidades inherentemente humanas con una alta carga peyorativa, ya que el sadismo es una perversión sexual que se está equiparando a una ley.

\section{Conclusiones}

El análisis pragmático llevado a cabo en este trabajo posibilita la confirmación parcial de la hipótesis de partida, según la cual habría una clara posición antiabortista en la prensa conservadora (ElMundo, $A B C$ y La Razón) y proabortista en la prensa de izquierdas (El Pais). Como ha quedado reflejado en varios momentos de la investigación, $A B C$ y $L a$ Razón no permiten vacilación alguna en su postura ideológica: la reforma de la ley del aborto es una necesidad perentoria para que se corrija el desorden causado por el PSOE en 2010 (Ley Orgánica 2/2010, de 3 de marzo, de salud sexual y reproductiva y de la interrupción voluntaria del embarazo).

El País, por su lado, se opone directamente a los principios estructurantes manifiestos en el anteproyecto de ley y la critica desde diferentes ángulos. Como consecuencia, nos encontramos con una defensa de las ideas de la izquierda progresista y un ataque a toda medida que venga del polo opuesto. La única excepción a la que nos hemos enfrentado ha sido la del periódico $E l$ Mundo. 
Aunque nosotros lo clasificamos ideológicamente como conservador (centro-derecha) y por lo tanto esperábamos que no se opusiera a la propuesta del PP, el análisis de los titulares nos dice lo contrario. De forma general, se aboga por la defensa de los derechos de la mujer y se critica el carácter restrictivo de la nueva ley. Como hemos apuntado en las páginas precedentes, su actitud es más moderada que la de El País, aunque ambos navegan en la misma dirección.

Respecto a los objetivos del trabajo, el primero perseguía un examen ideológico de nuestro corpus lingüístico, pero centrándonos en los estudios de Grize (1996) y Thompson (1993) sobre la transmisión de la ideología. Para lograrlos, hemos descrito los distintos titulares agrupándolos por temáticas y poniéndolos en constante diálogo para que aflorasen más claramente las diferencias. El análisis que ha expuesto palmariamente la ideología latente en cada uno de los diarios, así como los recursos lingüísticos, semánticos o tipográficos que refuerzan cada una de las tesis informativas.

Finalmente, el segundo objetivo pretendía reconocer el lenguaje metafórico que se ha utilizado en los titulares de prensa como vehículo para transmitir la ideología. Del examen se desprende un uso de la metáfora íntimamente ligado al refuerzo de un punto de vista ideológico concreto. Ningún uso del lenguaje retórico es arbitrario sino que las palabras, ahora más que nunca, se cargan de matices semánticos que hacen muy difícil la disociación binaria ideología-lenguaje.

\section{Bibliografía}

Bakhtin, M. y V. N. Vološinov (1989), "Discourse in Life and Discourse in Art (Concerning Sociological Poetics)”, en Davis, Robert Con y Ronald Schleifer [eds.], Contemporary Literary Criticism: Literary and Cultural Studies, Nueva York y Londres: Longman.

Blommaert, J. (2006), "Language ideology", en Brown, Keith [ed.], Encyclopedia of Language \& Linguistics, vol. 6, Oxford: Elsevier.

Durkheim, E. (2006), Sociología y filosofia, Granada: Comares.

Fisher, Frank y Herbert Gottweis (2012) [eds.], The argumentative turn revisited: public policy as communicative practice, Durham y Londres: Duke University Press.

Grize, Jean-Blaise (1982), "Quelques operations de la logique natural”, en Grize, Jean-Blaise [ed.], De la logique a l'argumentation, Genève: Librairie Droz.

Grize, Jean-Blaise (1990), Logique et langage, París: Ophrys.

Grize, Jean-Blaise (1996), Logique naturelle et communications, París: PUF.

Guijarro Ojeda, Juan Ramón (2013), “Queering English studies: paving the way towards social justice”, en Díaz Pérez, Francisco et al. [ed.], Global issues and the teaching of language literature and linguistics, Suiza: Peterlang. 
Raúl Ruiz-Cecilia y Juan Ramón Guijarro-Ojeda. Lenguaje e ideología. A propósito de la nueva ley del aborto española

Gutiérrez Vidrio, Silvia (1998), “Posición ideológica y uso del lenguaje en la prensa mexicana”, en Cortés Bargalló, Luis, Carlos García-Tort y Carlos Mapes [eds.], La lengua española y los medios de comunicación, vol. 1, México: Siglo XXI editores.

Gutiérrez Vidrio, Silvia (2003), "El discurso argumentativo. Una propuesta de análisis”, en Escritos, Revista del Centro de Ciencias del Lenguaje, núm. 27, vol. 1, México: UNAM. Lakoff, George y Mark Johnson (2007), Metáforas de la vida cotidiana, Madrid: Cátedra.

Sánchez García, Francisco José (2010), Pragmática de los titulares politicos. Las estrategias implícitas de persuasión ideológica, Madrid: Visor.

Searle, John (1990), Actos de habla: ensayo de filosofía del lenguaje, Madrid: Cátedra.

Silverstein, M. (2003), "Indexical order and the dialectics of social life", en Language and communication, núm. 23, vol. 3-4, USA: Elsevier.

Thompson, John B. (1986), "Language and Ideology: A Framework for Analysis”, en The Sociological Review, núm. 3, vol. 35, USA: John Wiley \& Sons.

Thompson, John B. (1993), Ideología y cultura moderna, México: UAM-Xochimilco.

Zorrilla Barroso, José Manuel (2002), El titular de la noticia. Estudio de los titulares informativos en los diarios de difusión nacional, Madrid: Universidad Complutense de Madrid.

\section{Recursos electrónicos}

$A B C$ (2013), núm. 20 de diciembre de 2013. Disponible en: http://hemeroteca.abc.es/nav/ Navigate.exe/hemeroteca/madrid/abc/2013/12/20.html [21 de junio de 2014].

$A B C$ (2013), núm. 21 de diciembre de 2013. Disponible en: http://hemeroteca.abc.es/nav/ Navigate.exe/hemeroteca/madrid/abc/2013/12/21.html [21 de junio de 2014].

$A B C$ (2013), núm. 23 de diciembre de 2013. Disponible en: http://hemeroteca.abc.es/nav/ Navigate.exe/hemeroteca/madrid/abc/2013/12/23.html [20 de junio de 2014].

Corpus Diacrónico del Español (CORDE) (2016). Disponible en: http://www.rae.es/ recursos/banco-de-datos/corde [25 marzo 2016].

DRAE (2016). Disponible en: http://www.rae.es [1 marzo 2016].

El País (2013), núm. 20 de diciembre de 2013. Disponible en: http://elpais.com/ hemeroteca/elpais/2013/12/20/t/portada.html [20 de junio de 2014].

El País (2013), núm. 21 de diciembre de 2013. Disponible en: http://elpais.com/ hemeroteca/elpais/2013/12/21/t/portada.html [20 de junio de 2014].

El Mundo (2013), núm. 21 de diciembre de 2013. Disponible en: http://www.elmundo.es/ elmundo/hemeroteca/2013/12/21/t/index.html [20 de junio de 2014].

El Mundo (2013), núm. 23 de diciembre de 2013. Disponible en: http://www.elmundo.es/ elmundo/hemeroteca/2013/12/23/t/index.html [20 de junio de 2014].

La Razón (2013), núm. 20 de diciembre de 2013. Disponible en: www.larazon.es [20 de junio de 2014]. La Razón (2013), núm. 21 de diciembre de 2013. Disponible en: www.larazon.es [20 de junio de 2014].

La Razón (2013), núm. 22 de diciembre de 2013. Disponible en: www.larazon.es [20 de junio de 2014].

Sánchez García, Francisco José (2009), Estudio pragmático del discurso periodístico político español. A propósito de los debates sobre el estado de la nación. Tesis doctoral, Granada: Editorial Universidad de Granada. Disponible en: http://0-hera.ugr.es.adrastea.ugr. es/tesisugr/18426074.pdf [20 de mayo de 2014]

Van Dijk, Teun Adrianus (1999), "Un estudio lingüístico de la ideología”, en Parodi Sweis, Giovanni [ed.], Discurso, cognición y Educación. Ensayos en honor a Luis A. Gómez Macker, Valparaíso: Ediciones Universitarias de Valparaíso dela UCV.Disponible en: http://www. biblioargentina.gob.ar/archivos/adcurso/estudio_1_\%20ideologia.pdf[28 de julio de 2014]. 


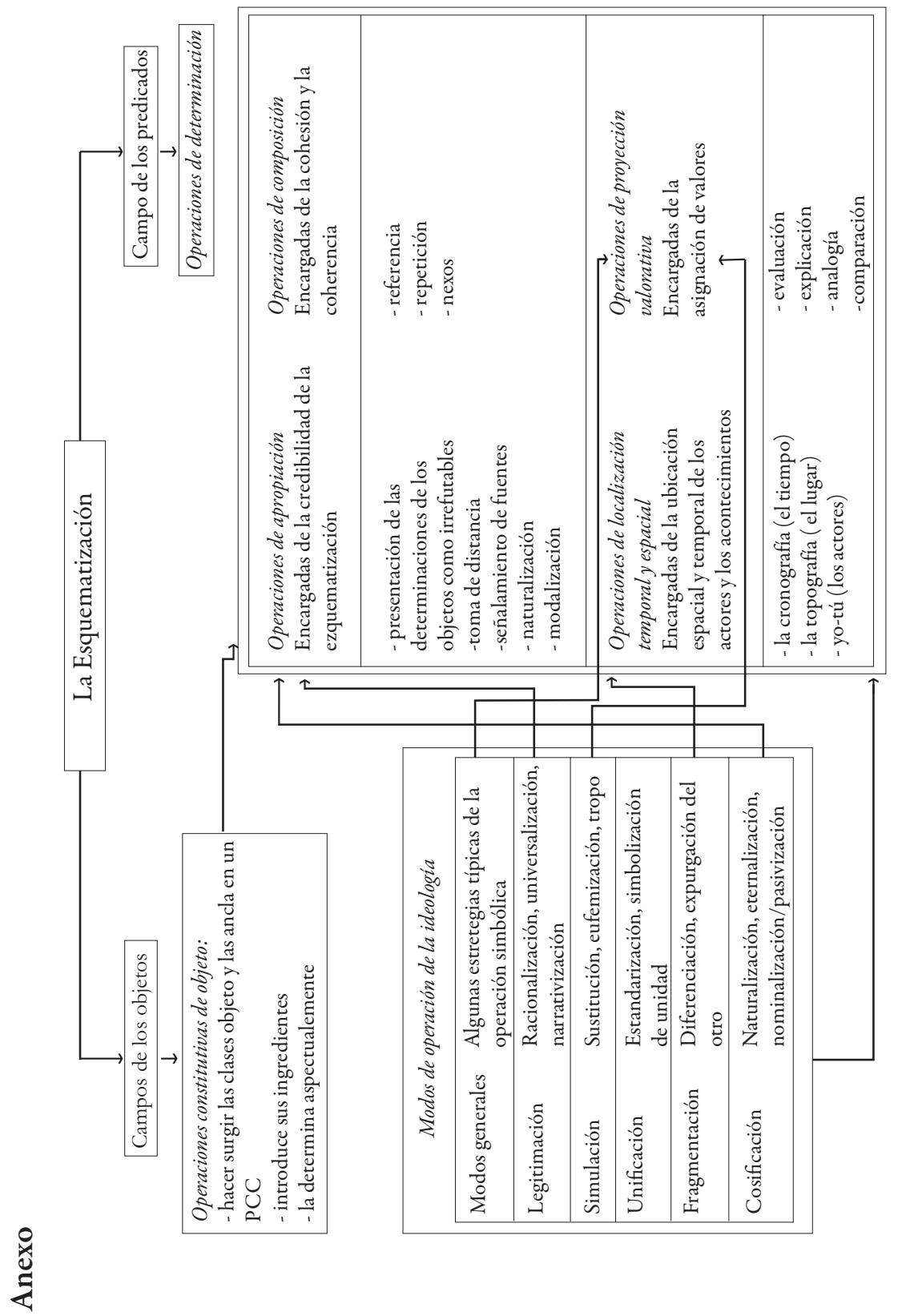




\section{Tabla 1}

\section{Titulares de prensa}

\begin{tabular}{|c|c|c|c|}
\hline $\begin{array}{l}\text { (ELM 1) La ley } \\
\text { del aborto coloca a } \\
\text { España a la cola de } \\
\text { Europa. }\end{array}$ & $\begin{array}{l}\text { (ELP 1) El } \\
\text { Gobierno } \\
\text { aprueba la ley } \\
\text { del aborto más } \\
\text { restrictiva de la } \\
\text { democracia. }\end{array}$ & $\begin{array}{l}\text { (ABC 1) Doce } \\
\text { preguntas y } \\
\text { respuestas para } \\
\text { entender la } \\
\text { reforma de la ley } \\
\text { del aborto. }\end{array}$ & $\begin{array}{l}\text { (LAR 1) PP: el aborto } \\
\text { «nunca puede ser un } \\
\text { derecho» sino una } \\
\text { «excepción». }\end{array}$ \\
\hline $\begin{array}{l}\text { (ELM 2) Pasar a la } \\
\text { prehistoria. }\end{array}$ & $\begin{array}{l}(\mathrm{ELP} 2) \mathrm{Ni} \\
\text { rastro de las } \\
\text { medidas contra } \\
\text { la "violencia } \\
\text { estructural". }\end{array}$ & $\begin{array}{l}\text { (ABC 2) El PP } \\
\text { dice que el aborto } \\
\text { nunca puede ser } \\
\text { un derecho sino } \\
\text { una excepción. }\end{array}$ & $\begin{array}{l}\text { (LAR 2) El triunfo } \\
\text { de la vida ante } \\
\text { la adversidad. } \\
\text { Compromiso con la } \\
\text { vida. }\end{array}$ \\
\hline $\begin{array}{l}\text { (ELM 3) El PP } \\
\text { responde al PSOE } \\
\text { que el aborto } \\
\text { nunca puede ser un } \\
\text { 'derecho' sino una } \\
\text { excepción. }\end{array}$ & $\begin{array}{l}\text { (ELP 3) Se } \\
\text { prohíbe la } \\
\text { publicidad de } \\
\text { las clínicas que } \\
\text { hacen abortos. }\end{array}$ & $\begin{array}{l}\text { (ABC 3) El PSOE } \\
\text { frenará una ley que } \\
\text { han hecho «los } \\
\text { enemigos de las } \\
\text { mujeres». }\end{array}$ & $\begin{array}{l}\text { (LAR 3) Entre } \\
1985 \text { y } 2011 \text { se } \\
\text { han practicado } 1,7 \\
\text { millones de abortos en } \\
\text { España. }\end{array}$ \\
\hline $\begin{array}{l}\text { (ELM 4) Derecho } \\
\text { a Vivir critica } \\
\text { que la ley permita } \\
\text { abortar a una } \\
\text { violada porque } \\
\text { 'castiga a un } \\
\text { inocente'. }\end{array}$ & $\begin{array}{l}\text { (ELP 4) La } \\
\text { oposición y las } \\
\text { organizaciones } \\
\text { feministas cargan } \\
\text { contra la reforma. }\end{array}$ & $\begin{array}{l}\text { (ABC 4) Mejora } \\
\text { la ley, la tarea } \\
\text { continúa. }\end{array}$ & $\begin{array}{l}\text { (LAR 4) Para } \\
\text { la Conferencia } \\
\text { Episcopal, «dentro } \\
\text { de lo malo, es menos } \\
\text { malo». }\end{array}$ \\
\hline $\begin{array}{l}\text { (ELM 5) El PSOE } \\
\text { promete 'parar' } \\
\text { la 'ley del aborto } \\
\text { dictada por la } \\
\text { extrema derecha'. }\end{array}$ & $\begin{array}{l}\text { (ELP 5) } \\
\text { Anomalías } \\
\text { gravísimas e } \\
\text { incurables pero } \\
\text { no mortales, sin } \\
\text { amparo. }\end{array}$ & $\begin{array}{l}\text { (ABC 5) El PSOE } \\
\text { insta a las } 76 \\
\text { diputadas del PP a } \\
\text { rechazar la reforma } \\
\text { del aborto. }\end{array}$ & $\begin{array}{l}\text { (LAR 5) La «defensa } \\
\text { de la vida } » \text { del PSOE: } \\
\text { un aborto cada cinco } \\
\text { minutos. }\end{array}$ \\
\hline $\begin{array}{l}\text { (ELM 6) } \\
\text { Partidarios de la } \\
\text { sanidad pública } \\
\text { tachan de 'sádica' } \\
\text { la nueva ley del } \\
\text { aborto. }\end{array}$ & $\begin{array}{l}\text { (ELP 6) El } \\
\text { aborto fuera de la } \\
\text { ley será un delito } \\
\text { sin sanción para } \\
\text { las gestantes. }\end{array}$ & $\begin{array}{l}\text { (ABC 6) Rajoy } \\
\text { cumple con la } \\
\text { reforma del aborto. }\end{array}$ & $\begin{array}{l}\text { (LAR 6) Fin al } \\
\text { coladero del aborto. }\end{array}$ \\
\hline
\end{tabular}




\begin{tabular}{|c|c|c|c|}
\hline $\begin{array}{l}\text { (ELM 7) La mujer } \\
\text { deberá reflexionar } \\
7 \text { días antes de } \\
\text { abortar. }\end{array}$ & $\begin{array}{l}\text { (ELP 7) Regreso } \\
\text { al pasado. }\end{array}$ & $\begin{array}{l}\text { (ABC 7) Claves y } \\
\text { nuevos requisitos } \\
\text { para acreditar el } \\
\text { aborto despenali- } \\
\text { zado por parte de } \\
\text { la mujer. }\end{array}$ & $\begin{array}{l}\text { (LAR 7) «Supondrá } \\
\text { eliminar el derecho de } \\
\text { las mujeres a decidir } \\
\text { libremente». }\end{array}$ \\
\hline $\begin{array}{l}\text { (ELM 8) La nueva } \\
\text { ley del aborto 'exi- } \\
\text { ge' riesgo psíquico } \\
\text { para la madre. }\end{array}$ & $\begin{array}{l}\text { (ELP 8) El } \\
\text { PSOE apela a } \\
\text { las diputadas del } \\
\text { PP y pedirá voto } \\
\text { secreto en la ley } \\
\text { del aborto. }\end{array}$ & $\begin{array}{l}\text { (ABC 8) Diferen- } \\
\text { cias entre las refor- } \\
\text { mas del aborto del } \\
\text { PSOE y del PP. }\end{array}$ & $\begin{array}{l}\text { (LAR 8) Aborto: sólo } \\
\text { en caso de riesgo para } \\
\text { la madre o violación. }\end{array}$ \\
\hline $\begin{array}{l}\text { (ELM 9) Una ley } \\
\text { más adecuada a la } \\
\text { doctrina del TC. }\end{array}$ & $\begin{array}{l}\text { (ELP 9) Las } \\
\text { verdades a medias } \\
\text { para limitar el } \\
\text { supuesto de mal- } \\
\text { formación. }\end{array}$ & $\begin{array}{l}\text { (ABC 9) El aborto } \\
\text { se limita al riesgo } \\
\text { grave para la salud } \\
\text { de la madre y a la } \\
\text { violación. }\end{array}$ & $\begin{array}{l}\text { (LAR 9) El PSOE se } \\
\text { compromete a «pa- } \\
\text { rar» una ley que trata } \\
\text { a las mujeres como } \\
\text { «incapaces». }\end{array}$ \\
\hline $\begin{array}{l}\text { (ELM 10) Las mu- } \\
\text { jeres sólo podrán } \\
\text { abortar con dos } \\
\text { informes psiquiá- } \\
\text { tricos. }\end{array}$ & $\begin{array}{l}\text { (ELP 10) "Cató- } \\
\text { lica o no, la mujer } \\
\text { debe ser libre de } \\
\text { decidir si aborta". }\end{array}$ & $\begin{array}{l}\text { (ABC 10) Las aso- } \\
\text { ciaciones pro vida, } \\
\text { satisfechas con la } \\
\text { reforma. }\end{array}$ & \\
\hline $\begin{array}{l}\text { (ELM 11) Alarma } \\
\text { entre las mujeres y } \\
\text { satisfacción en los } \\
\text { provida. }\end{array}$ & $\begin{array}{l}\text { (ELP 11) El } \\
\text { PSOE promete } \\
\text { parar la ley del } \\
\text { aborto que trata a } \\
\text { las mujeres como } \\
\text { "incapaces". }\end{array}$ & $\begin{array}{l}\text { (ABC 11) } \\
\text { Gallardón: «El } \\
\text { PSOE rompió el } \\
\text { consenso con la ley } \\
\text { de plazos». }\end{array}$ & \\
\hline $\begin{array}{l}\text { (ELM 12) La } \\
\text { izquierda y los na- } \\
\text { cionalistas coinci- } \\
\text { den: «Es la norma } \\
\text { más restrictiva de } \\
\text { Occidente». }\end{array}$ & $\begin{array}{l}\text { (ELP 12) La } \\
\text { violación sí es } \\
\text { un supuesto, la } \\
\text { malformación no. }\end{array}$ & $\begin{array}{l}\text { (ABC 12) «Iba en } \\
\text { nuestro programa } \\
\text { electoral y está en } \\
\text { la misma línea que } \\
\text { la ley aprobada } \\
\text { por el PSOE en } \\
1985 » .\end{array}$ & \\
\hline $\begin{array}{l}\text { (ELM 13) El PP } \\
\text { aplaude la «seguri- } \\
\text { dad jurídica » y el } \\
\text { «peso» médico. }\end{array}$ & $\begin{array}{l}\text { (ELP 13) "Somos } \\
\text { maduras para de- } \\
\text { cidir solas sobre } \\
\text { el embarazo". }\end{array}$ & & \\
\hline
\end{tabular}




\begin{tabular}{ll}
\hline & $\begin{array}{l}\text { (ELP 14) Un } \\
\text { proceso lleno de } \\
\text { obstáculos. }\end{array}$ \\
& $($ ELP 15) El su- \\
puesto de salud lo \\
abarca casi todo. \\
(ELP 16) Decá- \\
logo de la "Ley \\
de Protección \\
de la Vida del \\
Concebido".
\end{tabular}

Raúl Ruiz Cecilia. Doctor en Didáctica de la Lengua y la Literatura. Institución de adscripción: Universidad de Granada, España. Líneas de investigación: enseñanza de lenguas extranjeras, literatura multicultural, análisis crítico del discurso, lenguaje e ideología y estudios de género. Publicaciones recientes: Guijarro Ojeda, J.R. y R. Ruiz Cecilia, "Perceptions of Spanish EFL trainee teachers on the introduction of queer issues in the classroom", en Onomázein 27, junio, (2013); Ruiz Cecilia, R., "Estudio empírico sobre la incidencia del léxico en la comprensión de la lengua extranjera”, en $R L A$. Revista de lingüística teórica y aplicada, vol. 51, núm. 2 (2013); Pérez-Valverde, C. y R. Ruiz Cecilia, “The development of FL teachers' professional identity through the production of narratives", en Portalinguarum, núm. 22, (2014).

Juan Ramón Guijarro Ojeda. Doctor en Didáctica de la Lengua y la Literatura. Institución de adscripción: Universidad de Granada, España. Líneas de investigación: análisis crítico del discurso, estudios de género, formación del profesorado de lenguas. Publicaciones recientes: Guijarro Ojeda, Juan Ramón y Raúl Ruiz Cecilia, "Los discursos del género en Español Lengua Extranjera: A propósito de Pedro Almodóvar", en Hispania. A Journal Devoted to the Teaching of Spanish and Portuguese, vol. 94, núm. 1 (2011); Guijarro Ojeda, Juan Ramón y Raúl Ruiz Cecilia, "Perceptions of Spanish EFL trainee teachers on the introduction of queer issues in the classroom", en Onomázein: Revista de Lingüistica, Filología y Traducción, vol. 27, núm. 1 (2013); Barozzi, Stefano y Juan Ramón Guijarro Ojeda, "Sexual identities in EFL at primary school level: A pre-service teachers' perspective from Spain”, en Porta Linguarum, vol. 25, núm. 1 (2016).

Recepción: 14 de diciembre de 2014.

Aprobación: 18 de febrero de 2016. 
